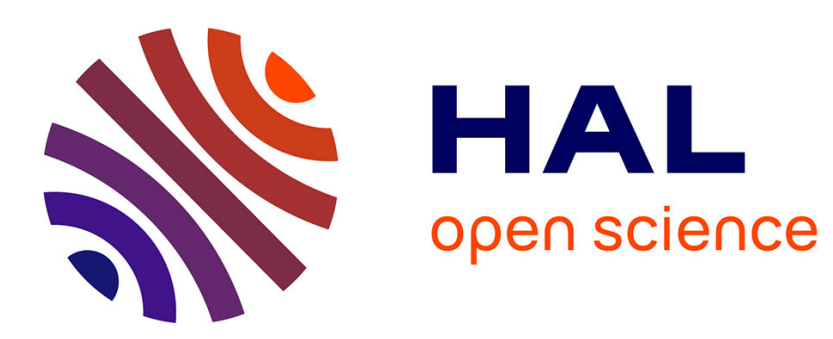

\title{
The ATLAS liquid argon electromagnetic calorimeter construction status
}

\author{
A. Jeremie
}

\section{To cite this version:}

A. Jeremie. The ATLAS liquid argon electromagnetic calorimeter construction status. International Conference on Advanced Technology and Particle Physics.8 ICATPP-8, Oct 2003, Como, Italy. pp.208212. in2p3-00014123

\section{HAL Id: in2p3-00014123 https://hal.in2p3.fr/in2p3-00014123}

Submitted on 14 Nov 2003

HAL is a multi-disciplinary open access archive for the deposit and dissemination of scientific research documents, whether they are published or not. The documents may come from teaching and research institutions in France or abroad, or from public or private research centers.
L'archive ouverte pluridisciplinaire HAL, est destinée au dépôt et à la diffusion de documents scientifiques de niveau recherche, publiés ou non, émanant des établissements d'enseignement et de recherche français ou étrangers, des laboratoires publics ou privés. 
LAPP-EXP 2003-19

November 2003

\title{
The ATLAS liquid argon electromagnetic calorimeter construction status
}

\author{
A. Jérémie \\ LAPP-IN2P3-CNRS \\ 9 chemin de Bellevue - BP. 110 \\ F-74941 Annecy-le-Vieux Cedex
}

Presented at 8th ICATPP Conference on Astroparticle, Particle, Space Physics,

Detectors and Medical Physics Applications, Como, Italie, October 6-10, 2003 


\title{
THE ATLAS LIQUID ARGON ELECTROMAGNETIC CALORIMETER CONSTRUCTION STATUS
}

\author{
A.JEREMIE* \\ LAPP-IN2P3-CNRS \\ 9 ch. de Bellevue, BP 110 \\ F-74941 Annecy-le-Vieux Cedex, FRANCE \\ E-mail: jeremie@lapp.in2p3.fr
}

\begin{abstract}
The ATLAS liquid argon electromagnetic calorimeter is currently in the final construction phase. The accordion design both for the Barrel and for the End-Cap detectors has proven a great challenge during the assembly. The well advanced construction, production, and assembly of the calorimeter is presented. The results of the tests performed for the final qualification of the detector are described.
\end{abstract}

\section{Introduction}

The ATLAS detector on the LHC is equipped with a liquid argon electromagnetic (EM) calorimeter ${ }^{1}$. The chosen calorimeter is built with accordion geometry composed of lead absorbers, liquid argon as ionizing medium and highly granular readout electrodes. The latter are divided into sectors with growing size from the interaction point starting with the strips for photon $/ \pi^{0}$ seperation. Then come the middle cells where the main energy deposit occurs. Further away from the interaction point are the back and barrel-end sectors for the high energy shower measurements. The ATLAS liquid argon EM calorimeter is composed of the Barrel and two End-caps, preceded by presampler sectors for reconstructing energy lost in the inner detectors. The EM Barrel calorimeter (figure 1) consists of 32 modules (2 wheels, $\mathrm{M}$ and $\mathrm{P}$ ) with 54848 readout channels and 64 presampler sectors with 7808 channels. Five construction sites contribute (Annecy, Saclay, CERN, Grenoble and Stockholm). For the EM End-cap calorimeter (figure 2), there are 16 modules for 2 wheels (ECC and ECA). In total, there are 62208 readout channels for the End-cap, and 1536 for the presampler.

* On behalf of the ATLAS EM Group 
Three construction sites contribute (Marseille, Madrid and Novosibirsk).

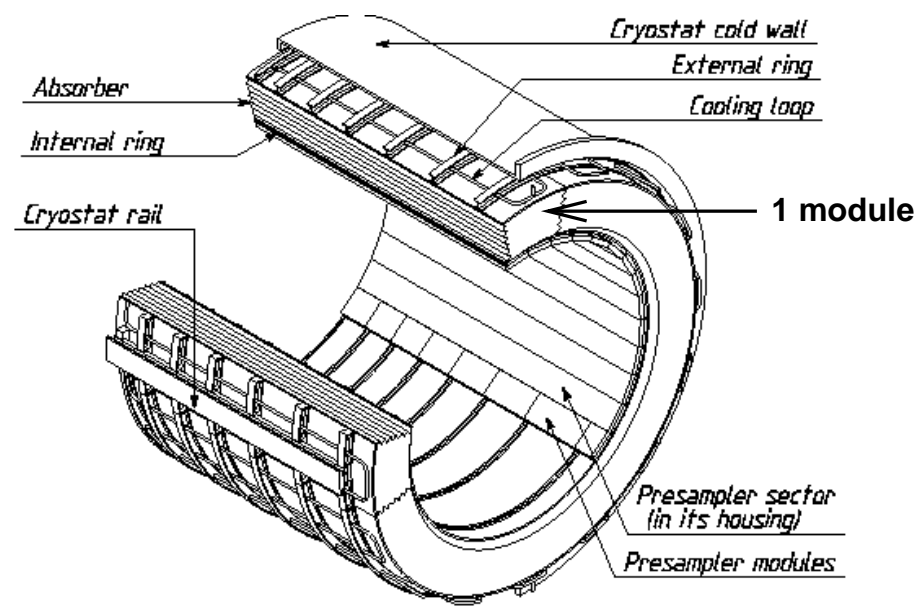

Figure 1. EM calorimeter 1/2 Barrel

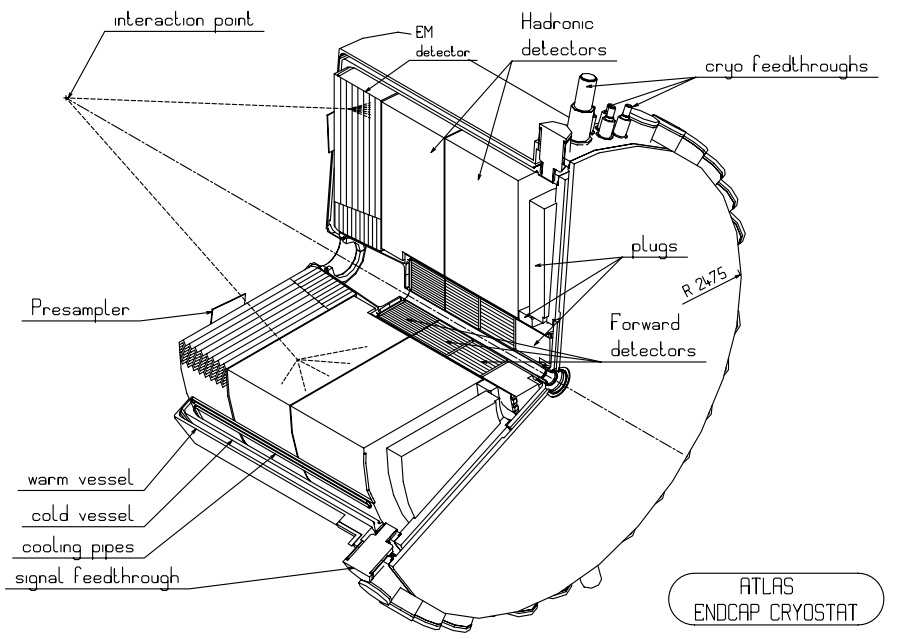

Figure 2. End-cap EM calorimeter together with the other End-cap detectors 


\section{Qualification tests}

During the construction phase, every component of the detector goes through qualifying steps. The description given here concerns the Barrel construction, but the tests are the same for the other detector components, only the duration of tests and the HV values differ. The principles of the electrical tests are described elsewhere ${ }^{2}$. The construction starts with module stacking which consists of assembling the signal and HV electrodes with the spacers and lead absorbers in accordion geometry. Geometrical measurements with precision gauge are performed during stacking and on the complete module. Gap thickness measurements are done with a capacimeter. Electrical continuity of the $\mathrm{HV}$ distribution is verified by sending a low frequency sinusoïd on the $\mathrm{HV}$ lines with capacitive readout on the signal layer. The module HV performance is controlled at $2200 \mathrm{~V}$ for 1 to 5 days. Module assembly takes about two months.

The module is subsequently cabled for the HV distribution, calibration and signal readout. Electrical continuity and HV tests are performed again. Detecting cabling errors and testing the whole calibration chain is done by sending a pulse through the calibration circuit with signal readout. Cabling takes a couple of weeks.

The final step consists of repeating the previous tests under cold conditions in liquid argon on site or on the beam test facility at CERN. The cold test takes about 1 month during which $2000 \mathrm{~V}$ is kept on the module for 5 days. Some modules are tested with a test beam to verify the detector performance (see contribution by R.Sacco ${ }^{3}$ ). Each module has to meet the qualifying criteria in order to pass to the next step. The modules are then sent to CERN for the final construction assembly. During this phase, the same tests are again performed on the assembled calorimeter after insertion in the cryostats.

\section{Construction status and electrical measurements}

The final assembly phase is well under way. The EM Barrel has its first wheel (M) of 16 modules inside the cryostat (figure 3) and electrically tested. The tests on the inserted wheel have shown that all but 4 out of 54848 readout channels satisfy the qualification criteria. The second wheel (P) has been inserted into the cryostat on September 9, 2003. Mechanical surveys have been performed on both wheels, confirming the expected shape which has to be taken into account for physics reconstruction. The $\mathrm{P}$ wheel is currently under electrical test. The cold tests in the definitive 


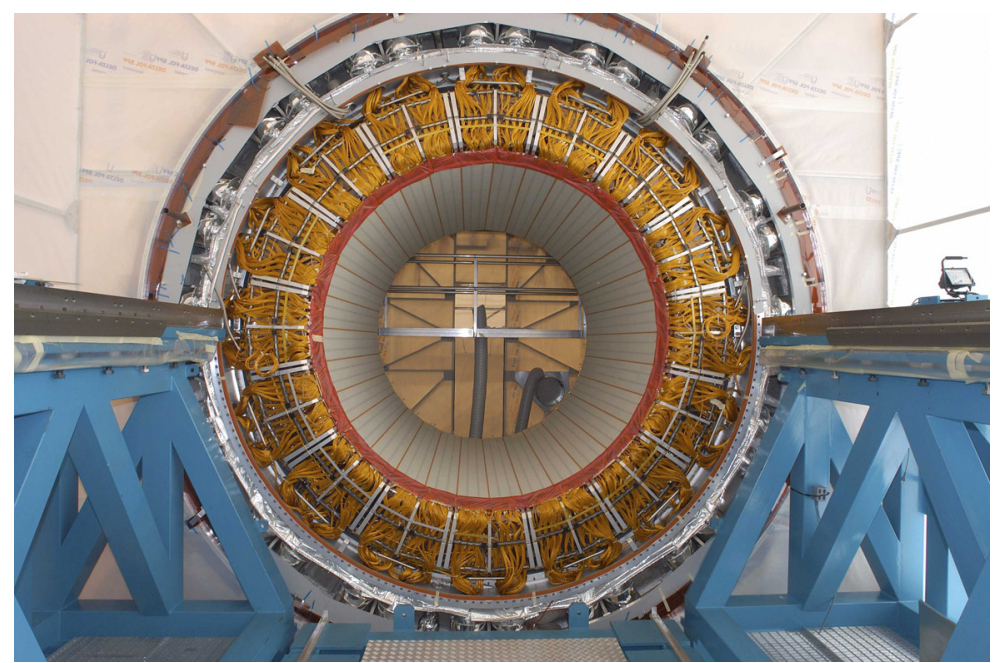

Figure 3. EM Barrel M wheel inside barrel cryostat (May 2003)

cryostat will follow. The Barrel presampler has both wheels inserted and tested.

Some additional measurements have been performed on the inserted M wheel. The precision calibration resistances on the motherboards sitting on the detector inside the cryostat have been measured with a dedicated setup installed on the cryostat signal feedthrough. Table 1 summarises the results, giving the number of resistances that are outside the $\pm 0.2 \%$ of the prescribed value. In total, 50 out of 58386 (one per mil) are in this case.

Table 1. Number of resistances outside $\pm 0.2 \%$ of prescribed value.

\begin{tabular}{|c|r|}
\hline Detector sector & Number of resistance/Total (result in \%) \\
\hline Presampler & $5 / 3904(0.1 \%)$ \\
Strips & $16 / 28672(0.05 \%)$ \\
Middle & $13 / 14336(0.07 \%)$ \\
Back and barrel -end & $12 / 12556(0.13 \%)$ \\
Termination & $4 / 3410(0.05 \%)$ \\
\hline
\end{tabular}

The first End-Cap wheel (ECC) is inserted in its cryostat and is currently under test (figure 4). Measurements on the front cells have shown that there are 3 dead channels and 7 strange ones out of 13824 tested until now. Integration of the second wheel will take place in spring 2004 . 


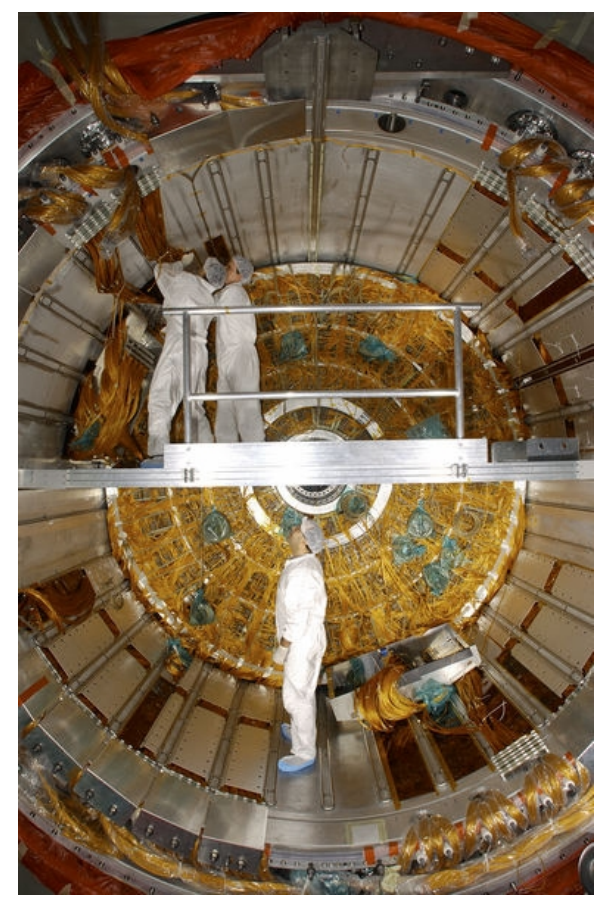

Figure 4. EM End-cap ECC wheel inside End-cap cryostat (August 2003)

Electrical tests of 36 EM End-cap presampler modules have been finished November 2002.

\section{Conclusion}

The construction of the ATLAS Liquid Argon electromagnetic calorimeter is well advanced. The same tests as described in this article will be performed in Liquid Argon in the final cryostat. When all these tests are completed, the EM calorimeter will be ready for ATLAS integration planned for 2004 .

\section{References}

1. The ATLAS collaboration, ATLAS Liquid Argon Calorimeter TDR CERN/LHCC/96-41 (December 15 1996).

2. N. Massol in : Proc. VIII Int. Conf. on Calorimetry in High Energy Phys., Lisbon, Portugal, June 1999 , p.161.

3. R.Sacco, these proceedings. 